\title{
THE EFFECT OF BREATHING EXERCISES IN PULMONARY EMPHYSEMA
}

\author{
BY \\ J. D. SINCLAIR* \\ From Green Lane Hospital, Auckland, New Zealand
}

(RECEIVED FOR PUblication MARCH 30, 1955)

One of the few forms of treatment available for those who suffer from pulmonary emphysema is breathing exercises taught by physiotherapists. Generally, these exercises aim at assisting active expiration, teaching general physical relaxation, and increasing the efficiency of respiratory work. They require much time and effort from both the patient and his teacher, yet until recently there had been no survey of their effects. Some physicians believed them to be of real value, but others, such as Donald (1953), considered them " a convenient placebo, an indirect form of psychotherapy."

Becklake, McGregor, Goldman, and Braudo (1954) recently performed lung function tests before and after physiotherapy, found no improvement, and concluded that the subjective benefits claimed by patients arose from a subconscious desire to please those who were treating them. On the other. hand, Miller (1954) reported considerable improvement in lung function after a similar investigation.

The same problem was examined in the present survey.

\section{Material AND Methods}

Patients investigated were those who showed clinical, radiographic, and physiological signs of emphysema, who had no other disease contributing to their disability, had not previously learned breathing exercises, and were not receiving other new treatment concurrent with physiotherapy. Twenty-two patients formed the main group. The first 10 were examined repeatedly at short intervals; the others were examined before treatment and afterwards at intervals varying from three to 12 weeks, according to the frequency of their attendance, their ability to continue attending, and the satisfaction of the physiotherapist that maximum improvement had been obtained.

The exercises were given by senior physiotherapists at intervals varying from daily to weekly. They were

\footnotetext{
* New Zealand Medical Research Council Fellow in Chest Diseases, 1953-54.
}

very similar to those described by Reed (1952), the $\stackrel{f}{\circ}$ patient being taught to recognize the incoordination 을 of his breathing, to correct this by increasing his abdominal (and therefore his diaphragmatic) breath- $\vec{c}$ ing, and to relax the excessive movement of the upper thorax and shoulder girdle.

The vital capacity and its components were recorded as the average of three readings when these were consistent. The functional residual capacity was measured by the nitrogen elimination technique of Cournand, Baldwin, Darling, and Richards (1941); of residual and total capacities were calculated from this. Duplicate tests were required to agree within $500 \mathrm{ml}$. The maximum breathing capacity was measured on a light Benedict-Roth spirometer; the better of two consistent tests was accepted; the patients were standing. Ventilatory volumes at rest were measured in a 100-litre spirometer. Oxygen $\vec{\Rightarrow}$ uptake was measured by spirometry. Intrapulmonary gas-mixing efficiency was recorded as alveolar nitrogen per cent after seven minutes' oxygen breathing. Arterial oxygen saturations were measured by a spectrophotometric technique. All gas volumes were corrected to those at body temperature and ambient pressures.

Diaphragm excursion was measured as the maximum movement of the midpoint of each diaphragm, with the patient standing. The measurements were made by adjustable horizontal clips on a vertical rule. No correction was made for geometric distortion, which should have been small.

In a later group of patients, vertical movement of $\frac{T}{0}$ the thoracic cage during respiration was measured from the movement of lead rubber attached to the $N$ anterior chest wall at the level of the sternoxiphisternal junction.

\section{RESULTS}

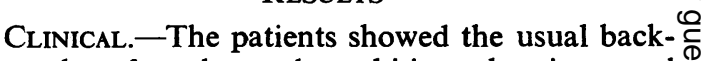
grounds of asthma, bronchitis, wheezing, and $\stackrel{\oplus}{\sim}$ increasing breathlessness. Several had become ill since an attack of pneumonia; some had been "gassed" in the war of 1914-18. In the main $\stackrel{\mathbb{D}}{\circ}$ group there were 20 men and two women. The $\frac{\vec{D}}{}$ physical and radiographic signs were those $\frac{\varrho}{\sigma}$ 
TABLE I

AGE AND SEX OF PATIENTS AND IMPROVEMENT AFTER COURSE OF BREATHING EXERCISES

\begin{tabular}{|c|c|c|c|c|c|c|c|c|c|c|c|c|}
\hline & \multirow{3}{*}{$\begin{array}{c}\text { Age } \\
\text { (Years) }\end{array}$} & \multirow{3}{*}{ Sex } & \multirow{3}{*}{$\begin{array}{c}\text { Length } \\
\text { of } \\
\text { Treatment } \\
\text { (Weeks) }\end{array}$} & \multirow{3}{*}{$\begin{array}{c}\text { Subjective } \\
\text { Improvement }\end{array}$} & \multirow{2}{*}{\multicolumn{2}{|c|}{$\begin{array}{l}\text { Vital Capacity } \\
\text { (ml.) }\end{array}$}} & \multirow{2}{*}{\multicolumn{2}{|c|}{$\begin{array}{c}\text { Maximum Breathing } \\
\text { Capacity } \\
\text { (litres } / \text { min.) }\end{array}$}} & \multicolumn{4}{|c|}{$\begin{array}{l}\text { Maximum Diaphragmatic } \\
\text { Excursion (cm.) }\end{array}$} \\
\hline & & & & & & & & & \multicolumn{2}{|c|}{ Before } & \multicolumn{2}{|c|}{ After } \\
\hline & & & & & Before & After & Before & After & R. & L. & R. & L. \\
\hline $\begin{array}{l}\text { G. McC. } \\
\text { W. Tr. } \\
\text { W. Te. } \\
\text { H. N. } \\
\text { W. P. } \\
\text { L. Y. } \\
\text { S. McC. } \\
\text { J. W. } \\
\text { C. K. } \\
\text { W. F. } \\
\text { A. Hw. } \\
\text { N. L. } \\
\text { G. H. } \\
\text { T. P. } \\
\text { H. L. } \\
\text { H. N. } \\
\text { A. Hy. } \\
\text { L. A. } \\
\text { W. C. } \\
\text { G. McF. } \\
\text { R. L. } \\
\text { E. B. }\end{array}$ & $\begin{array}{l}37 \\
48 \\
62 \\
56 \\
50 \\
60 \\
54 \\
46 \\
50 \\
61 \\
63 \\
51 \\
49 \\
65 \\
68 \\
70 \\
56 \\
54 \\
60 \\
32 \\
37 \\
54\end{array}$ & $\begin{array}{l}\mathbf{M} \\
\mathbf{M} \\
\mathbf{M} \\
\mathbf{M} \\
\mathbf{M} \\
\mathbf{M} \\
\mathbf{M} \\
\mathbf{M} \\
\mathbf{M} \\
\mathbf{M} \\
\mathbf{M} \\
\mathbf{M} \\
\mathbf{M} \\
\mathbf{M} \\
\mathbf{M} \\
\mathbf{F} \\
\mathbf{M} \\
\mathbf{M} \\
\mathbf{M} \\
\mathbf{F} \\
\mathbf{M} \\
\mathbf{M}\end{array}$ & $\begin{array}{r}5 \\
6 \\
12 \\
3 \\
12 \\
5 \\
2 \\
12 \\
12 \\
6 \\
14 \\
3 \\
10 \\
7 \\
3 \\
8 \\
12 \\
5 \\
12 \\
15 \\
7 \\
7\end{array}$ & $\begin{array}{c}0 \\
+ \\
++ \\
+ \\
++ \\
++ \\
0 \\
++ \\
+ \\
+ \\
0 \\
+ \\
0 \\
+ \\
0 \\
0 \\
0 \\
0 \\
++ \\
++ \\
++ \\
+\end{array}$ & $\begin{array}{l}3,600 \\
2,620 \\
2,790 \\
2,890 \\
3,280 \\
3,880 \\
3,550 \\
3,000 \\
2,265 \\
2,110 \\
3,280 \\
2,200 \\
1,620 \\
2,480 \\
2,300 \\
1,980 \\
2,740 \\
2,220 \\
2,330 \\
1,345 \\
1,890 \\
1,555\end{array}$ & $\begin{array}{l}3,330 \\
2,400 \\
2,510 \\
2,910 \\
3,140 \\
4,270 \\
4,310 \\
3,740 \\
2,050 \\
2,690 \\
3,370 \\
2,310 \\
1,680 \\
2,510 \\
2,530 \\
2,270 \\
2,410 \\
2,180 \\
3,630 \\
2,170 \\
2,280 \\
1,530\end{array}$ & $\begin{array}{r}195 \\
58 \\
76 \\
94 \\
60 \\
59 \\
48 \\
74 \\
25 \\
69 \\
56 \\
32 \\
38 \\
16 \\
31 \\
26 \\
30 \\
36 \\
29 \\
27 \\
24 \\
28\end{array}$ & $\begin{array}{r}215 \\
64 \\
70 \\
88 \\
87 \\
70 \\
59 \\
84 \\
27 \\
80 \\
73 \\
39 \\
31 \\
28 \\
32 \\
36 \\
24 \\
31 \\
34 \\
30 \\
50 \\
26\end{array}$ & $\begin{array}{r}4 \cdot 5 \\
3.0 \\
4 \cdot 0 \\
6.0 \\
-1.0 \\
6.0 \\
6.0 \\
4.0 \\
-1.0 \\
6.5 \\
2.0 \\
4.0 \\
3.0 \\
3.0 \\
5.0 \\
1.0 \\
3.0 \\
-1.0 \\
2.0 \\
-2.0 \\
-2.5 \\
1.0\end{array}$ & $\begin{array}{r}5 \cdot 0 \\
2.5 \\
4 \cdot 5 \\
6.5 \\
2.0 \\
5.0 \\
6 \cdot 5 \\
4.0 \\
-1.0 \\
6.5 \\
2.5 \\
2.0 \\
2.5 \\
2.0 \\
5.5 \\
2.0 \\
2.5 \\
-1.0 \\
2.0 \\
1.0 \\
-2.0 \\
2.0\end{array}$ & 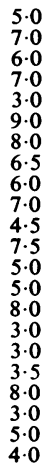 & $\begin{array}{l}7 \cdot 0 \\
5 \cdot 5 \\
6 \cdot 5 \\
8 \cdot 0 \\
5 \cdot 0 \\
9 \cdot 0 \\
8 \cdot 0 \\
7 \cdot 5 \\
6 \cdot 0 \\
7 \cdot 0 \\
5 \cdot 0 \\
5 \cdot 0 \\
5 \cdot 0 \\
6 \cdot 0 \\
8 \cdot 5 \\
3 \cdot 5 \\
3 \cdot 5 \\
3 \cdot 0 \\
8 \cdot 0 \\
5 \cdot 0 \\
6 \cdot 0 \\
2 \cdot 5\end{array}$ \\
\hline Mean & $53 \cdot 8$ & . & $8 \cdot 1$ & & 2,540 & 2,735 & $51 \cdot 4$ & $58 \cdot 0$ & $2 \cdot 6$ & $2 \cdot 8$ & $5 \cdot 7$ & 5.9 \\
\hline
\end{tabular}

expected. No patient had been in congestive heart failure.

After treatment seven patients claimed marked improvement, seven claimed moderate improvement, and eight felt the same as before. Several volunteered instances of their improved exercise tolerance, e.g., up stairs at work, while one could walk up a hill in 20 minutes where previously he always needed 40 minutes.

LUNG Function STUdiEs.-Functional residual capacities were estimated on 11 patients, arterial oxygen on 14 ; the other tests were carried out on all 22 patients.

The brief details of age and sex are given in Table I, together with the degree of subjective improvement with treatment, and vital and maximum breathing capacities before and after treatment. These were the tests that changed most, and in fact the improvement was not significant. Statistical analysis of both sets of figures gave $P>0.05$; i.e., there was a chance of more than one in 20 that the changes were coincidental. In the same table, maximum diaphragm excursion is shown to have increased markedly after physiotherapy, the improvement being obviously significant $(\mathrm{P}<0.001)$.

The results of these and other tests are shown in Table II. In none of them was there a significant improvement after treatment. Because the results differ little from those reported by Becklake and others (1954), the details are not shown.
All tests varied toward improvement on the reading after treatment, but this improvement was too small to be significant either statistically or physiologically. Most tests were worse as often as they were better on the second reading, the mean improvement coming from markedly better

TABLE II

MEAN RESULTS OF VARIOUS LUNG FUNCTION TESTS IN VARYING NUMBERS OF PATIENTS WITH EMPHYSEMA BEFORE AND AFTER BREATHING EXERCISES

\begin{tabular}{|c|c|c|c|c|}
\hline . & No. & $\begin{array}{c}\text { Before } \\
\text { Treatment }\end{array}$ & $\underset{\text { Treatment }}{\text { After }}$ & Difference \\
\hline $\begin{array}{l}\text { Vital capacity . . } \\
\text { Residual , } \\
\text { Functional residual }\end{array}$ & $\begin{array}{l}22 \\
11\end{array}$ & $\begin{array}{l}2,540 \mathrm{ml} \text {. } \\
2,930, \text {, }\end{array}$ & $\begin{array}{l}2,735 \mathrm{ml} \text {. } \\
2,755 ~,\end{array}$ & $\begin{array}{l}+195 \text { c.c. } \\
-175, "\end{array}$ \\
\hline $\begin{array}{cc}\text { capacity } & \ldots \\
\text { Total capacity } & \cdots\end{array}$ & $\begin{array}{l}11 \\
11\end{array}$ & $\begin{array}{l}3,990 \quad, \\
5,566 \quad,\end{array}$ & $\begin{array}{l}3,770, \\
5,543 \quad,\end{array}$ & $\begin{array}{r}-220, \\
-23,\end{array}$ \\
\hline $\begin{array}{l}\text { R.C. } \% \quad \ldots \\
\text { T.C. \% } \\
\text { F.R.C. } \% \ldots\end{array}$ & $\begin{array}{l}11 \\
11\end{array}$ & $\begin{array}{l}54 \cdot 2 \% \\
71 \cdot 5 \%\end{array}$ & $\begin{array}{l}49 \cdot 7 \% \\
66 \cdot 4 \%\end{array}$ & $\begin{array}{l}-4 \cdot 5 \% \\
-5 \cdot 1 \%\end{array}$ \\
\hline $\begin{array}{l}\text { Maximum breath- } \\
\text { ing capacity .. }\end{array}$ & 22 & $51.41 . \mathrm{min}$. & $58.01 . / \mathrm{min}$ & $+6.61 . / \mathrm{min}$. \\
\hline Minute ventilation & 19 & $9 \cdot 5 \quad$, & $9.6 \quad$, & $+0.1 \quad$, \\
\hline $\begin{array}{l}\text { Intrapulmonary } \\
\text { mixing efficiency } \\
\left.\text { (alveolar } \mathrm{N}_{2} \%\right) \\
\end{array}$ & 21 & $5 \cdot 1 \%$ & $4.8 \%$ & $-0.3 \%$ \\
\hline $\begin{array}{c}\text { Resting arterial } \\
\mathrm{HbO}_{2}\end{array}$ & 14 & $89 \%$ & $90 \%$ & $+1 \%$ \\
\hline $\begin{array}{l}\text { Maximum dia- } \\
\text { phragm excur- } \\
\text { sion (mean of } \\
\text { two sides) }\end{array}$ & 22 & $2.7 \mathrm{~cm}$ & $5.8 \mathrm{~cm}$ & $+3 \cdot 1 \mathrm{~cm}$ \\
\hline
\end{tabular}


results in a small number of patients. The diaphragm excursion improved in all patients, the vital capacity improved in 14 of 22 , and the maximum breathing capacity in 16 of 22 .

Five patients showed appreciable improvement when tested after treatment. They had no common factor to account for their improvement ; they were of widely different ages; four were men and one was a woman; there was nothing special about the aetiology of their disease, the manner of its onset, their features on physical examination, or the severity of their symptoms.

These patients all claimed marked subjective improvement; otherwise there was little relationship between subjective improvement and the changes in lung function.

Further Analysis of Diaphragmatic MoveMENT.-It was clear that the increase in diaphragm excursion was not related to other measurements. For example, one patient increased the diaphragm movement by $7 \mathrm{~cm}$. on each side with an accompanying fall of $200 \mathrm{ml}$. in his vital capacity. It had been noted during screening that diaphragmatic movement was often jerky before treatment and smooth afterwards; that accurate measurement of its movement was often spoiled by the tendency of the patients to lift the entire chest walls during inspiration so that the diaphragm fell relative to the ribs but rose with the chest wall and thus it was sometimes at a higher level in full inspiration than in full expiration. This movement appeared to account for part, at least, of the " jump-back pattern" described by Abbott, Hopkins, Van Fleit, and Robinson (1953). After breathing exercises this phenomenon was seldom seen.

Wade (1954) overcame this error in measuring true diaphragmatic excursion by measuring chest wall movement as well, and correcting the apparent diaphragmatic excursion accordingly. He thus measured true diaphragmatic excursion.

Using a comparable technique, a further group of nine patients with emphysema were examined before and after treatment. Their vital capacities and maximum breathing capacities were measured, together with the maximum diaphragmatic excursion; with the latter, vertical movement of the chest wall was measured by noting the movement of opaque rubber attached to the skin over the lower sternum. The patients were reasonably comparable with those previously examined.

The results are shown in Table III. The vital capacity and maximum breathing capacity improved a little, and the diaphragmatic excursion improved a great deal. But when allowance was made for changes in chest wall movement, the diaphragmatic excursion was the same after treatment as before; the real change after breathing exercises was in the chest wall movement. Beforehand there was a marked lifting of the chest wall in inspiration and some lowering in expiration, probably from extension and flexion of the spine. This movement was stopped by physiotherapy, sometimes within the first two sessions.

Diaphragmatic excursion corrected in this way was found to be as high in patients with emphysema as it was in normal subjects relative to the vital capacity. In nine patients it averaged 2.7 $\mathrm{cm}$. per $1,000 \mathrm{ml}$. of vital capacity compared with $2.6 \mathrm{~cm}$. per $1,000 \mathrm{ml}$. in 10 normal patients examined by Wade (1954). Thus the apparent severe reduction in diaphragmatic movement in emphysema is largely fallacious.

\section{Discussion}

Any physiological benefits of breathing exercises in emphysema should be shown by a rise in vital capacity and maximum breathing capacity, a fall

TABLE III

THE EFFECT OF BREATHING EXERCISES IN A FURTHER GROUP OF PATIENTS

\begin{tabular}{|c|c|c|c|c|c|c|c|c|c|c|c|}
\hline & \multirow{3}{*}{$\begin{array}{c}\text { Subjective } \\
\text { Improvement }\end{array}$} & \multicolumn{2}{|c|}{$\begin{array}{l}\text { Vital Capacity } \\
\text { (ml.) }\end{array}$} & \multicolumn{2}{|c|}{$\begin{array}{l}\text { Maximum Breathing } \\
\text { Capacity (litres/min.) }\end{array}$} & \multicolumn{4}{|c|}{$\begin{array}{c}\text { Diaphragm } \\
\text { Excursion (cm.) }\end{array}$} & \multicolumn{2}{|c|}{$\begin{array}{l}\text { Vertical Chest } \\
\text { Movement (cm.) }\end{array}$} \\
\hline & & \multirow{2}{*}{ Before } & \multirow{2}{*}{ After } & \multirow{2}{*}{ Before } & \multirow{2}{*}{ After } & \multicolumn{2}{|c|}{ Before } & \multicolumn{2}{|c|}{ After } & \multirow{2}{*}{ Before } & \multirow{2}{*}{ After } \\
\hline & & & & & & $\mathbf{R}$. & L. & R. & L. & & \\
\hline $\begin{array}{l}\text { T. P. } \\
\text { A. B. } \\
\text { R. M. } \\
\text { G. B. } \\
\text { A. G. } \\
\text { J. E. } \\
\text { K. C. } \\
\text { J. P. } \\
\text { W. D. }\end{array}$ & $\begin{array}{l}+ \\
++ \\
++ \\
++ \\
+ \\
++ \\
++ \\
++ \\
0\end{array}$ & $\begin{array}{l}3,080 \\
2,260 \\
4,950 \\
3,200 \\
3,450 \\
3,000 \\
1,000 \\
1,800 \\
2,570\end{array}$ & $\begin{array}{l}3,550 \\
2,160 \\
5,060 \\
3,410 \\
3,100 \\
3,630 \\
1,070 \\
2,640 \\
2,840\end{array}$ & $\begin{array}{r}128 \\
37 \\
101 \\
99 \\
40 \\
76 \\
18 \\
23 \\
64\end{array}$ & $\begin{array}{r}128 \\
28 \\
113 \\
102 \\
52 \\
88 \\
31 \\
30 \\
63\end{array}$ & $\begin{array}{l}8 \\
1 \cdot 5 \\
6 \\
6 \\
4 \\
4 \\
2 \\
-1 \\
5\end{array}$ & $\begin{array}{l}9 \\
4 \\
6 \\
4 \cdot 5 \\
6 \\
4 \cdot 5 \\
2 \\
-1 \\
6 \cdot 5 \\
\end{array}$ & $\begin{array}{l}8 \cdot 5 \\
5 \\
6 \\
8 \\
4 \\
7 \\
4 \cdot 5 \\
4 \cdot 0 \\
8\end{array}$ & $\begin{array}{l}9 \cdot 5 \\
5 \\
5 \cdot 5 \\
5 \cdot 5 \\
6 \\
8 \cdot 5 \\
4 \cdot 5 \\
4 \cdot 0 \\
7\end{array}$ & $\begin{array}{l}3 \\
3 \\
6 \\
4 \\
3 \\
5 \cdot 5 \\
3 \cdot 5 \\
3 \\
2\end{array}$ & $\begin{array}{l}3 \\
1 \\
2 \cdot 5 \\
2 \\
3 \\
2 \cdot 5 \\
0 \cdot 5 \\
2 \cdot 5 \\
0\end{array}$ \\
\hline Mean & & 2,815 & 3,050 & 65 & 70 & $4 \cdot 0$ & $4 \cdot 5$ & $6 \cdot 1$ & $6 \cdot 2$ & 3.7 & 1.9 \\
\hline
\end{tabular}

The mean diaphragm excursion before treatment was $4.25 \mathrm{~cm}$. and after treatment $6.15 \mathrm{~cm}$. The corrected diaphragm excursione before treatment was $7.95 \mathrm{~cm}$., and after treatment $8.05 \mathrm{~cm}$. 
in residual and functional residual capacities, and improvement in intrapulmonary gas mixing and in arterial oxygen saturation. If changes arose they should have been demonstrated by the tests used, but they were not. This investigation, therefore, agreed with the findings of Becklake and others (1954) that lung function tests showed little improvement in patients given breathing exercises for emphysema. The marked improvements found by Miller (1954) were not confirmed in local patients. Miller did not prove that his changes were not from a learning effect or from the natural progress of disease in his patients, some of whom were apparently recovering from recent severe infections and heart failure. Possibly, but less likely, his physiotherapy was more effective than that used locally, for he used "certain important modifications" yet to be described.

The evidence that patients did not improve their real diaphragmatic movement after breathing exercises agrees with the finding of Wade (1954) that in normal people there is no voluntary control of diaphragmatic movement. He showed that its clinical assessment depended on spinal movement with corresponding retraction or protrusion of the ventral abdominal wall. The only other control of diaphragm movement was in the depth of respiration.

The one measurable change with breathing exercises was the reduction in chest wall movement in deep respiration. This was undoubtedly an inefficient accessory movement of the shoulder girdle and spine. It remains to be argued whether reduction of this excessive movement was enough to account for the patients' claims of subjective improvement of dyspnoea.

The feeling of breathlessness has been shown by Cournand and his associates (e.g., Cournand and Richards, 1941) to correspond with the relationship of the ventilation rate to the maximum breathing capacity. They have concluded that breathlessness is an awareness of respiratory effort approaching $40 \%$ of the patient's maximum. That other factors may sometimes be involved is shown by occasional patients who are breathless despite normal ventilation rate and maximum breathing capacity when the work done in achieving ventilation is increased by a low vital capacity in extensive pulmonary tuberculosis, or in the presence of bilateral pleural effusions, or with a diaphragmatic paralysis. It must therefore be possible that patients with emphysema are breathless, in part, because of the inefficient and excessive work done by the accessory muscles of respiration. When this extra work is reduced by physiotherapy they achieve the same results as before with less effort and therefore feel less breathless. This is an explanation of the benefits of physiotherapy which has previously been suggested by physicians (Christie, 1944; Oswald, 1954) and has been reasonably confirmed in the present investigation. Apart from this, it cannot be denied that many patients claim unreal benefits in order to please those who show an interest in them.

\section{SUMMARY}

Twenty-two patients with emphysema showed slight but not significant improvement in lung function after a course of breathing exercises. All showed marked improvement in maximum diaphragm excursion.

Further analysis of nine patients showed that the apparent increase in diaphragm excursion arose from diminished vertical movement of the chest wall ; true diaphragm excursion was not altered by treatment.

It was concluded that the only physical benefit of breathing exercises was in reducing inefficient spinal and shoulder girdle movement in respiration. The exercises should therefore be directed toward this end.

I wish to thank the New Zealand Medical Research Council for the Fellowship and other financial aid; the Auckland Hospital Board for providing facilities; Drs. C. McDowell and J. R. Hinds and other hospital physicians for much guidance and for permitting examination of their patients; Mr. Douglas Robb for his assistance ; the physiotherapists for their long and keen cooperation; and many patients who willingly gave their time to this research.

\section{REFERENCES}

Abbott, O. A., Hopkins, W. A., Van Fleit, W. E., and Robinson, J. S. (1953). Thorax, 8, 116.

Becklake, M. R., McGregor, M., Goldman, H. I., and Braudo, J. L. (1954). Dis. Chest, 26, 180.

Christie, R. V. (1944). Brit. med. J., 1, 105 and 143.

Cournand, A., Baldwin, E. de F., Darling, R. C., and Richards, D. W. (1941). J. clin. Invest., 20,681. and Richards, D. W. (1941). Amer. Rev. Tuberc., 44, 26.

Donald, K. W. (1953). Brit. med. J., 1, 415 and 473.

Monald, K. W. (1953). Brit. Med. J., 1, 415 an.

Oswald, N. C. (1954). Amer. J. Med.,

Reed, J. M. W. (1952). In Diseases of the Chest, 1st ed., Ch. 32, edited by Sir G. Marshall and K. M. A. Perry. Butterworth. London.

Wade, O. L. (1954). J. Physiol., Lond., 124, 193. 